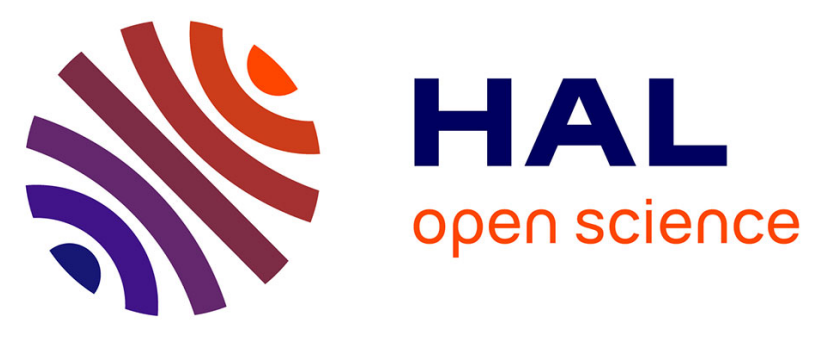

\title{
Two Different Composite Markers Predict Severity and Threshold Dose in Peanut Allergy
}

\author{
Nathalie Cottel, Sarah Saf, Mélisande Bourgoin-Heck, Nathalie Lambert, \\ Flore Amat, Pascal Poncet, Helene Senechal, Rémy Couderc, Jocelyne Just, \\ Yannick Chantran
}

\section{To cite this version:}

Nathalie Cottel, Sarah Saf, Mélisande Bourgoin-Heck, Nathalie Lambert, Flore Amat, et al.. Two Different Composite Markers Predict Severity and Threshold Dose in Peanut Allergy. Journal of Allergy and Clinical Immunology: In Practice, 2020, 10.1016/j.jaip.2020.09.043 . hal-03009456

\section{HAL Id: hal-03009456 https://hal.sorbonne-universite.fr/hal-03009456}

Submitted on 24 Nov 2020

HAL is a multi-disciplinary open access archive for the deposit and dissemination of scientific research documents, whether they are published or not. The documents may come from teaching and research institutions in France or abroad, or from public or private research centers.
L'archive ouverte pluridisciplinaire HAL, est destinée au dépôt et à la diffusion de documents scientifiques de niveau recherche, publiés ou non, émanant des établissements d'enseignement et de recherche français ou étrangers, des laboratoires publics ou privés. 


\title{
Two Different Composite Markers Predict Severity and Threshold Dose in Peanut Allergy
}

\author{
Nathalie Cottel, MD ${ }^{a}$, Sarah Saf, MD ${ }^{a}$, Melisande Bourgoin-Heck, MD ${ }^{a, b}$, Nathalie Lambert, MD ${ }^{a}$, Flore Amat, MD, PhD ${ }^{a, b}$, \\ Pascal Poncet, $\mathrm{PhD}^{\mathrm{c}, \mathrm{d}}$, Helene Senechal, $\mathrm{PhD}^{\mathrm{c}}$, Rémy Couderc, $\mathrm{PhD}^{\mathrm{c}}$, Jocelyne Just, MD, PhD ${ }^{\mathrm{a}, \mathrm{b}}$, and \\ Yannick Chantran, PharmD ${ }^{\mathrm{c}}$ Paris, France
}

What is already known about this topic? Peanut allergy is one of the most frequent causes of anaphylaxis in children with food allergies. Oral food challenge remains the gold standard to evaluate the threshold dose and severity of peanut allergy.

What does this article add to our knowledge? This study reports the relevance of allergen-specific and non-allergenspecific basophil activation test parameters to determine the severity and threshold dose of a peanut-allergic reaction in children.

How does this study impact current management guidelines? Introduction of these multivariable models in routine practice could avoid an oral food challenge in some children with peanut allergy.

BACKGROUND: Safe and cost-effective biological surrogate markers to evaluate the severity and threshold dose of peanut allergy (PA) reactions during an oral food challenge (OFC) are lacking.

OBJECTIVE: To evaluate biological markers associated with the severity and threshold dose of an allergic reaction during an OFC in a population of children with PA.

METHODS: Demographic and biological parameters of children with peanut OFC and basophil activation test (BAT) results were collected. Patients were stratified into 2 severity groups (mild-to-moderate and severe) and 2 cumulative threshold dose groups: low (LCTG) $\leq 100 \mathrm{mg}$ crushed peanut and high $>100 \mathrm{mg}$.

RESULTS: Among the 68 children included, there was a $96 \%$ concordance between the OFC and BAT result for the diagnosis of PA. Of the 56 children with a positive OFC and BAT to peanut (median age: 8.8 years), the severity of an allergic reaction and the cumulative threshold dose were not correlated $(P=.24)$. Higher Ara h 2 -specific IgE and FceRI-positive control values were both associated with severe reactions to peanut. Combining these 2 markers led to a $92 \%$ sensitivity $(84 \%-97 \%)$ and an $82 \%$ specificity $(71 \%-89 \%)$ for severe

\footnotetext{
aAllergology Department, Hôpital A. Trousseau, Sorbonne Université, AP-HP, Paris, France

${ }^{\mathrm{b}}$ Epidemiology of Allergic and Respiratory Diseases, IPLESP, INSERM and Sorbonne Université, Paris, France

${ }^{c}$ Immunology Department, Biological Allergology Unit, Hôpital A. Trousseau, Sorbonne Université, AP-HP, Paris, France

${ }^{\mathrm{d}}$ Immunology Department, Institut Pasteur, Paris, France

No funding was received for this work.

Conflicts of interest: M. Bourgoin-Heck has received lecture fees from Stallergenes Green. N. Lambert has received lecture fees from Stallergenes Green, AstraZeneca, and Novartis. F. Amat has received lecture fees from Novartis, ALK, and Mead Johnson. J. Just is on the boards for ALK-Abelló, Stallergenes Green, AstraZeneca, and Novartis; and has received research support from Novartis,
}

reactions in all subjects. For children in the LCTG, a 4-variable composite marker, including age, normalized basophil sensitivity $\left(\mathrm{EC}_{50}\right)$, and FceRI- and fMLP-positive control values, resulted in a $97 \%$ sensitivity $(89 \%-99 \%)$ and $61 \%$ specificity (49\%-71\%).

CONCLUSION: Distinct composite markers including BAT allergen-specific and non-allergen-specific parameters appear to be associated with severity and cumulative threshold dose in children with PA. (C) 2020 American Academy of Allergy, Asthma \& Immunology (J Allergy Clin Immunol Pract 2020; : $\mathbf{- m}$ - )

Key words: Peanut allergy; Basophil activation test; FceRI-positive control; Oral food challenge

Peanut allergy (PA) is one of the most frequent food allergies in children accounting for $25 \%$ of food allergies overall. ${ }^{1,2} \mathrm{PA}$ is diagnosed before the age of 6 in approximately $80 \%$ of children with PA. ${ }^{3}$ The prevalence of PA is increasing throughout the world, and self-reported allergy studies record a prevalence of $2.1 \%$ in the United States and from $0.3 \%$ to $0.75 \%$ in France. $^{4,5}$ In 2019, the incidence of food-induced anaphylaxis in Europe was higher compared with other regions in the word

Switzerland. The rest of the authors declare that they have no relevant conflicts of interest.

Received for publication January 20, 2020; revised September 17, 2020; accepted for publication September 18, 2020.

Available online $\mathbf{\square}$

Corresponding Jocelyne Just, MD, PhD, Service d'Allergologie, Groupe hospitalier Trousseau-La Roche Guyon, 26 Avenue du Dr. Arnold Netter, 75012 Paris, France. E-mail: jocelyne.just@aphp.fr.

2213-2198

(C) 2020 American Academy of Allergy, Asthma \& Immunology

https://doi.org/10.1016/j.jaip.2020.09.043 


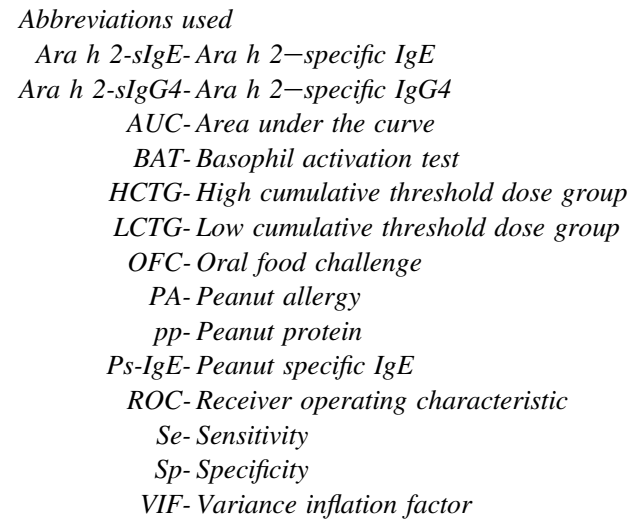

(America, Oceania, and Asia) ${ }^{6}$ - and more prevalent among children and adults younger than 24 years-resulting in an increase in hospitalizations for anaphylaxis." Along with the increased prevalence, the severity of allergic reactions to peanut has increased with PA being the most common cause of food anaphylaxis since 2007.,8 PA is rarely outgrown and tolerance develops in only $20 \%$ of cases. ${ }^{2,9}$ Current PA management is avoidance of culprit foods, which is risky, exposes subjects to accidental allergic reactions, and impairs quality of life. ${ }^{10,11}$

Oral food challenge (OFC) is the gold standard for the diagnosis of food allergy and to define severity and a threshold dose for a clinical reaction. ${ }^{12}$ However, OFC is resourceintensive, time-consuming, and carries a risk of anaphylaxis, ${ }^{13}$ justifying investigations for biological surrogates for diagnosis and to evaluate threshold dose and severity. Many studies have already demonstrated the usefulness of clinical and biological markers to diagnose PA to avoid an OFC. Among these markers, Ara h 2-specific IgE (Ara h 2-sIgE) levels and the basophil activation test (BAT) have been extensively studied. ${ }^{14-18}$ Although some studies have suggested that the association of these biomarkers could predict threshold dose during an OFC, fewer studies have focused on their usefulness in predicting the severity of an allergic reaction during an OFC. ${ }^{19-22}$ Some tools, mainly incorporating biological parameters, have been developed to stratify patients according to the severity of an allergic reaction during an OFC. ${ }^{23-26}$

In this context, the aim of our study was to assess the reliability of a model including BAT and various composite markers to predict the threshold dose and the severity of an allergic reaction during an OFC in children with PA.

\section{METHODS \\ Study design}

This was a retrospective cross-sectional study performed in patients in whom PA had been confirmed by an open OFC. Patients were recruited from February 2016 to April 2020 at the allergy department of Trousseau Hospital in Paris, France, a pediatric, university-based outpatient practice. We included all children (aged $<18$ years) who had been addressed for a peanut OFC for the following reasons: (1) suspected PA with doubtful allergic history and evidence of peanut specific $\operatorname{IgE}$ (ps-IgE) sensitization; or (2) evidence of ps-IgE sensitization with avoidance of peanut in their diet, and having undergone the BAT for the same indications.

\section{Parameter assessment}

Standardized open peanut OFC consisted of ingesting increasing doses of crushed peanut (Benenuts) — from 2 to $3000 \mathrm{mg}$ of peanut (0.56-840 mg of peanut protein [pp])—every 20 minutes for a total cumulative dose of $7100 \mathrm{mg}$ of peanut (1988 mg of pp). An OFC was considered positive on observation of objective symptoms (as defined by the European Academy of Allergy and Clinical Immunology or the modified 2010 World Allergy Organization grading system) and was considered negative when all doses were well tolerated. ${ }^{27}$ The allergic symptoms during an OFC were graded in severity using the French guidelines (see Table E1 in this article's Online Repository at www.jaci-inpractice.org). ${ }^{27-29}$

The patients were stratified into 2 score severity groups for analysis $^{29}$ : mild-to-moderate (scores I and II) allergic reaction and severe (scores III and IV when epinephrine was needed) allergic reaction during an OFC.

Patients were also stratified into 2 cumulative threshold dose groups defined in accordance with literature ${ }^{3,30,31}$ : a low cumulative threshold dose group (LCTG) and a high cumulative threshold dose group (HCTG) of allergic reactions, $\leq 100 \mathrm{mg}$ of crushed peanut (28 $\mathrm{mg}$ of $\mathrm{pp}$ ) and $>100 \mathrm{mg}$, respectively.

\section{Biological parameters}

The biological markers collected, on the same day of the OFC, were eosinophil count, total $\mathrm{IgE}$, ps-IgE and peanut specific IgG4, Ara h 2-sIgE, and Ara h 2-specific IgG4 (Ara h 2-sIgG4) levels (ImmunoCAP; Thermo Fisher Scientific, Uppsala, Sweden). The BAT was performed only once: either on the same day of the $\mathrm{OFC}$ or, if that was not possible for logistic reasons (availability of a flow machine and technicians), within a year only if ps- $\operatorname{IgE}$ and Ara h 2-sIgE levels were stable indicating no change in the allergy status.

BATs were carried out using the FlowCAST assay kit (Bühlmann Laboratories, Schönenbuch, Switzerland), according to the FK-CCR supplier procedure, and are briefly summarized below.

After gentle stirring, $50 \mu \mathrm{L}$ of whole blood was incubated with 50 $\mu \mathrm{L}$ of peanut extract solution at 100,10 , or $1 \mathrm{ng} / \mathrm{mL}$ for 15 minutes at $37^{\circ} \mathrm{C}$. Control conditions included $50 \mu \mathrm{L}$ of unstimulated negative activation buffer and $50 \mu \mathrm{L}$ of anti-FceRI antibody solution or fMLP solution (positive controls with nonspecific stimulation). Basophils were gated based on CCR3+/SSClow window on the negative control, and activated basophils on CCR3+/CD63+ window on the FceRI-positive control. The percentage of basophil activation was measured for each condition. A criterion of acceptability of a given sample was at least 1 of the 2 positive controls $>15 \%$. A sample was considered positive if 1 of the 3 tubes containing the peanut extract displayed a percentage of basophil activation $>15 \%$.

The following BAT parameters were considered for analysis:

- The absolute percentage of basophil activation without stimulation (negative control values).

- The absolute percentage of basophil activation with nonspecific stimulation (FceRI- and fMLP-positive control values).

- The absolute percentage of basophil activation at different concentrations of peanut extract.

- The absolute allergen concentration able to activate $50 \%$ of basophils $\left(\mathrm{EC}_{50}\right)$. 
TABLE I. Descriptive analysis of parameters associated with the severity of an allergic reaction during a peanut oral food challenge

\begin{tabular}{|c|c|c|c|c|}
\hline & \multirow[b]{2}{*}{$\begin{array}{l}\text { All PA subjects with } \\
\text { positive BAT }(n=56)\end{array}$} & \multicolumn{3}{|c|}{ Severity groups } \\
\hline & & $\begin{array}{l}\text { Mild-to-moderate* } \\
\quad(n=43)\end{array}$ & $\begin{array}{l}\text { Severe* } \\
(n=13)\end{array}$ & $P$ value \\
\hline \multicolumn{5}{|l|}{ Demographic characteristics } \\
\hline Age (y) & $9.5(6.90-14.02)$ & $9.7(7.2-13.8)$ & $9.2(6.6-14.0)$ & .62 \\
\hline Male/female (n) & $36 / 20$ & $28 / 15$ & $8 / 5$ & $>.99$ \\
\hline Astier score (I/II/III/IV) & $17 / 26 / 11 / 2$ & - & - & \\
\hline Cumulative threshold dose (mg of pp) & $80(20-317)$ & $77(17-258.5)$ & $200(37-317)$ & .72 \\
\hline \multicolumn{5}{|l|}{ Biological parameters } \\
\hline Eosinophilia $\left(10^{6}\right.$ cells $\left./ \mathrm{mm}^{3}\right)$ & $0.42(0.31-0.63)$ & $0.43(0.31-0.58)$ & $0.39(0.31-0.80)$ & .61 \\
\hline Total $\operatorname{IgE} \log 10\left(\mathrm{kU}_{\mathrm{A}} / \mathrm{L}\right)$ & $618(317-1139)$ & $439(261-823)$ & $1256(647-2177)$ & .02 \\
\hline Peanut-specific $\operatorname{IgE} \log 10\left(\mathrm{kU}_{\mathrm{A}} / \mathrm{L}\right)$ & $87(28.6-238.5)$ & $76.1(27.9-154)$ & $259(93.1-332)$ & .04 \\
\hline Ara h 2-specific $\operatorname{IgE} \log 10\left(\mathrm{kU}_{\mathrm{A}} / \mathrm{L}\right)$ & $43.0(11-105.5)$ & $37.3(51-69.5)$ & $136(43.9-168)$ & .02 \\
\hline Peanut-specific IgG4 (mg/L) & $0.53(0.19-1.18)$ & $0.53(0.19-1.03)$ & $0.56(0.19-2.59)$ & .66 \\
\hline Ara h 2-specific IgG4 (mg/L) & $0.12(0.06-0.5)$ & $0.11(0.06-0.35)$ & $0.21(0.05-1.49)$ & .33 \\
\hline \multicolumn{5}{|l|}{ Absolute peanut BAT parameters } \\
\hline Negative control & $0.4(0.01-1)$ & $0.3(0.01-1)$ & $0.4(0.01-0.7)$ & .19 \\
\hline FceRI-positive control & $83.4(76.1-90.8)$ & $81(70.8-87.8)$ & $92.4(89.3-93.8)$ & .01 \\
\hline fMLP-positive control & $34.0(21.9-45.1)$ & $31.1(21.1-42.5)$ & $41(26.1-56.9)$ & .04 \\
\hline $\begin{array}{l}\text { Absolute percentage of basophil activation at } 100 \mathrm{ng} / \\
\mathrm{mL} \text { of peanut extract }\end{array}$ & $69.0(47.0-86.5)$ & $65.9(46.4-83.3)$ & $84.4(60.3-90.2)$ & .50 \\
\hline $\begin{array}{l}\text { Absolute percentage of basophil activation at } 10 \mathrm{ng} / \\
\mathrm{mL} \text { of peanut extract }\end{array}$ & $56.6(11.2-85.1)$ & $55.6(11.0-83.8)$ & $72(29.6-88.7)$ & .56 \\
\hline $\begin{array}{l}\text { Absolute percentage of basophil activation at } 1 \mathrm{ng} / \mathrm{mL} \\
\text { of peanut extract }\end{array}$ & $5.2(0.5-40.6)$ & $4.3(0.5-35.5)$ & $12.1(0.4-53.3)$ & .52 \\
\hline Absolute basophil $\mathrm{EC}_{50}^{\dagger}(\mathrm{ng} / \mathrm{mL})$ & $97.1(37.5-144.7)$ & $95.8(36.6-136.0)$ & $120.3(70.0-168.2)$ & .48 \\
\hline Absolute basophil activation AUC & $8.9(1.8->100)$ & $10(2.2->100)$ & $6.3(0.1-33.4)$ & .37 \\
\hline \multicolumn{5}{|l|}{ Normalized peanut BAT parameters } \\
\hline $\begin{array}{l}\text { Normalized percentage of basophil activation at } 100 \\
\mathrm{ng} / \mathrm{mL} \text { of peanut extract }\end{array}$ & $89.4(74.8-99.3)$ & $89.1(74.7-98.6)$ & $98.0(85.4-99.4)$ & .43 \\
\hline $\begin{array}{l}\text { Normalized percentage of basophil activation at } 10 \\
n g / m L \text { of peanut extract }\end{array}$ & $76.8(13.5-102.8)$ & $73.7(13.3-104.8)$ & $87.0(31.4-98.8)$ & .94 \\
\hline $\begin{array}{l}\text { Normalized percentage of basophil activation at } 1 \mathrm{ng} / \\
\mathrm{mL} \text { of peanut extract }\end{array}$ & $5.9(0.7-50.0)$ & $5.6(0.7-41.0)$ & $14.6(0.4-55.2)$ & .66 \\
\hline Normalized basophil $\mathrm{EC}_{50}^{\dagger}(\mathrm{ng} / \mathrm{mL})$ & $131.0(51.8-177.1)$ & $126.4(51.6-174.8)$ & $148.1(74.4-177.7)$ & .92 \\
\hline Normalized basophil activation AUC & $6.7(0.1-60.0)$ & $6.8(0.9-61.1)$ & $4.4(0.1-29.1)$ & .90 \\
\hline
\end{tabular}

Values are expressed as count or medians (interquartile ranges). $P$ values $<.05$ are boldface for 2 group comparisons of qualitative variables by using Fisher's exact test and for 2 group comparisons of quantitative variables by using permutation 1-way analysis of variance tests.

$A U C$, Area under the curve; $B A T$, basophil activation test; $O F C$, oral food challenge; $P A$, peanut allergy; $p p$, peanut protein.

*Mild-to-moderate allergic reactions during a peanut OFC (Astier scores I and II). Severe allergic reactions during a peanut OFC (Astier scores III and IV).

$\dagger \mathrm{EC}_{50}=$ allergen concentration able to activate $50 \%$ of basophils.

- The absolute area under the curve (AUC) of basophil activation at different concentrations of peanut extract, calculated as follows: AUC $=(\%$ activation for $1 \mathrm{ng} / \mathrm{mL})+(\%$ activation for $10 \mathrm{ng} /$ $\mathrm{mL})+(\%$ activation for $100 \mathrm{ng} / \mathrm{mL}-\%$ activation for $1 \mathrm{ng} /$ $\mathrm{mL}) / 2$.

- The relative percentage of basophil activation, $\mathrm{EC}_{50}$, and AUC normalized against the FceRI-positive control value to take into account allergen-specific activation relative to the potential maximum activation of a given patient.

\section{Statistical analysis}

Statistical analyses and plots were performed with R (Version 3.3.2; R Foundation for Statistical Computing, Vienna, Austria). The MASS, DescTools, beeswarm, pROC, coin, and qwraps2 packages were used for analysis and plotting.
Fisher's exact test was used for 2 group comparisons of binomial variables. Permutation 1-way analysis of variance tests were used for 2 group comparisons of quantitative variables. Multivariable logistic regressions were used to define composite markers, based on the OFC-positive BAT-positive subgroup. The multivariable step-forward selection strategy was adopted including the variables displaying a $P$ value of $<.05$ by likelihood ratio tests and a significant drop in the residual variance, as compared with the $k-1$ variables model, using the $\chi^{2}$ test with $P<.05$. Variance inflation factors (VIFs) were computed to estimate multicollinearity between variables.

Model predictions for each individual in the whole cohort (including OFC/BAT discordant subjects) were computed using the weight coefficients found by the least-squares approach to the observed values of each variable. These predictions were compared with the actual classification of the subject, allowing analysis by 


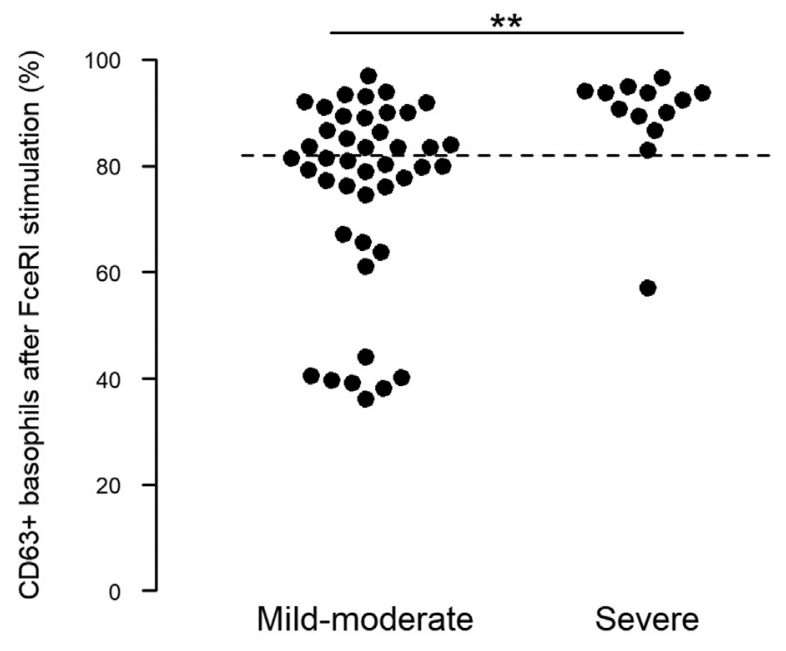

A

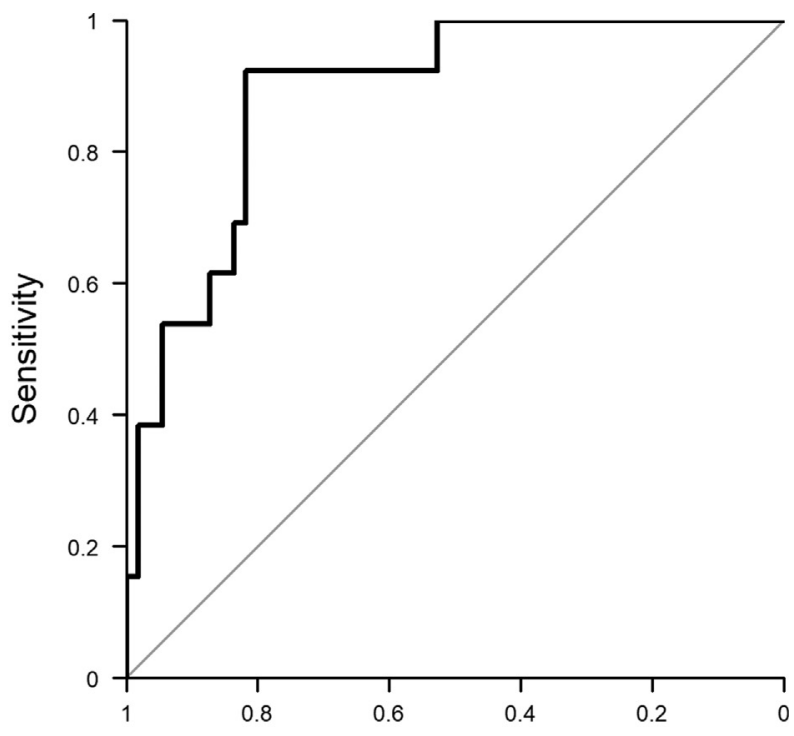

B

Specificity

FIGURE 1. A, Basophile activation test FceRI-positive control value in peanut-allergic patients presenting mild-to-moderate allergic reactions and severe allergic reactions during a peanut oral food challenge. ${ }^{*} P<.01$. B, Receiver operating characteristic curve of the multivariable logistic regression model presented in Table II (upper part) comparing the performances of this model in discriminating severe and nonsevere peanut-allergic children.

receiver operating characteristic (ROC) curves. Sensitivity (Se) and specificity (Sp) at best accuracy cutoffs for the candidate models of severity or cumulative threshold dose during an OFC were then computed.

All the tests were 2 -sided, with significant $P$ values below type I error risk $\alpha=0.05$. $\mathrm{EC}_{50}$ were log-transformed.

\section{Ethics}

Because all the procedures reflected routine patient care at the study center, the protocol was endorsed by the direct procedure of the Institutional Review Board of the Medical Ethics Committee on Research of AP-HP (http://recherche.aphp.fr/eds). ${ }^{32}$

\section{RESULTS}

\section{Population characteristics}

During the study period, 75 children with peanut OFC and available BAT results were considered for inclusion. Of these, 2 patients with subjective reactions during an OFC, negative peanut BAT, and negative Ara h 2-sIgE were excluded from analysis. Another 5 were excluded: 3 because of insufficient clinical information, and 2 because of uninterpretable peanut BAT for the other.

In the remaining 68 children with an OFC and BAT, 65 (96\%) presented concordant OFC and BAT results: 56 with a positive $\mathrm{OFC}$ and BAT, and 9 sensitized nonallergic children with a negative OFC and BAT. One child reacted during the OFC with a negative BAT, and 2 children presented a positive BAT without reacting during the OFC. This result confirms the BAT as a valuable surrogate marker for children with PA as compared with the OFC.

Among the 57 patients with a positive OFC, there was no apparent correlation between the severity of the allergic reaction and the cumulative threshold dose during an $\mathrm{OFC}(P=.27)$.
The demographic and biological characteristics of these patients are presented in Table I.

\section{Parameters associated with the severity of an allergic reaction during an OFC}

We aimed to correlate biological parameters, including BAT parameters, with the severity of allergic reactions, in the OFC/BAT-positive group. The severe allergic reaction group presented higher total IgE, ps-IgE, and Ara h 2-sIgE than the mild-to-moderate allergic reaction group $(P=.02, P=.04$, and $P=.02$, respectively) (Table I).

For BAT parameters associated with severity, higher FceRIand fMLP-positive control values were both associated with severe allergic reactions to peanut, being higher by $10 \%$ in severe patients $(P=.01$ and $P=.04$, respectively) (Table I). Illustratively, $92 \%$ (12 of 13 ) of the patients in the severe allergic reaction group presented an FcERI-positive control value above $82 \%$, as compared with $44 \%$ (19 of 43 ) in the mild-to-moderate allergic reaction group (Figure 1, $A$ ).

The multivariable linear regression model revealed that higher Ara h 2-sIgE and higher FceRI-positive control values were independently associated with the risk of a severe reaction (Table II, upper part). VIFs were below 1.1, indicating low multicollinearity. Of note, an increase in the FceRI-positive control value by $1 \%$ increased the risk of a severe reaction in the same order of magnitude as an increase of Ara h 2-sIgE by 10 $\mathrm{kU}_{\mathrm{A}} / \mathrm{L}$.

We investigated the relevance of this composite model to predict severe reactions in children with a suspicion of PA who would otherwise require an $\mathrm{OFC}$ by including nonallergic patients, OFC-positive BAT-negative, and OFC-negative BATpositive patients. The performances of this model were computed by ROC curve analysis with 0.89 (0.80-0.97) AUC. 
TABLE II. Multivariable logistic regression models to predict the severity and cumulative threshold dose of an allergic reaction

\begin{tabular}{|c|c|c|}
\hline & OR $(95 \% \mathrm{CI})$ per variable unit & $P$ values \\
\hline Severity model $(\mathrm{n}=55)^{*}$ & Higher risk of a severe reaction & \\
\hline Ara h 2-specific $\operatorname{IgE}\left(\mathrm{kU}_{\mathrm{A}} / \mathrm{L}\right)$ & $1.01(1.003-1.022)$ & .01 \\
\hline FceRI-positive control $(\%)$ & $1.10(1.023-1.248)$ & .047 \\
\hline Cumulative threshold dose model $(n=56)$ & Higher risk of reacting at a low cumulative threshold dose & \\
\hline Normalized basophil $\mathrm{EC}_{50} \times \log 10(\mathrm{ng} / \mathrm{mL})^{\ddagger}$ & $0.40(0.22-0.73)$ & .01 \\
\hline Age $(y)$ & $1.22(1.01-1.45)$ & .04 \\
\hline$\sqrt{ }($ FceRI $\times$ fMLP) positive controls $(\%)$ & $0.95(0.90-0.99)$ & .02 \\
\hline
\end{tabular}

All variables were tested by using forward multivariable logistic regression, and only variables contributing to the model $(P<.05)$ were retained. $P$ values $<.05$ are boldface. $C I$, Confidence interval; $O R$, odds ratio.

*Severity score was not recorded in 1 patient.

$\dagger$ Low cumulative threshold dose: $\leq 100 \mathrm{mg}$ of peanut (28 $\mathrm{mg}$ of peanut protein).

$\ddagger \mathrm{EC}_{50}=$ allergen concentration able to activate $50 \%$ of basophils.

Best accuracy provided $92 \%$ Se (84\%-97\%) and 82\% Sp (71\%89\%) (Figure 1, B).

The bivariate composite biomarker predicting severe allergic reactions to peanut was the following formula: Severity index $=-10.6+0.099 \times$ FceRI-positive control value $+0.0118 \times($ Ara h 2 -sIgE $)$. An index score $>-1.35$ predicted severe allergic reactions to peanut.

\section{Parameters associated with the cumulative threshold dose during an OFC}

A higher age was significantly associated with the LCTG compared with the HCTG $(P=.019)$ (Table III). In addition, higher ps-IgE or Ara h 2-sIgE levels were associated with a lower cumulative threshold dose $(P=.004$, and $P=.001$, respectively) (Table III).

Regarding the BAT parameters, all allergen-specific parameters indicated facilitated peanut-induced basophil activation in patients in the LCTG, with the exception of absolute percentage of basophil activation at $100 \mathrm{ng} / \mathrm{mL}$ of peanut extract, which was very close to statistical significance $(P=.06)$ (Table III). Interestingly, lower $P$ values were systematically obtained for BAT parameters after normalization against the FceRI-positive control value.

Multivariable logistic regression models indicated a higher risk of the low cumulative threshold dose of an allergic reaction in older children $(P=.05)$, patients with lower normalized $\mathrm{EC}_{50}$ $(P=.004)$, but also lower FceRI- and fMLP-positive control values $(P=.015)$ (Table II). Importantly, all 3 factors contributed significantly and independently to the model, with a significant drop in residual variance compared with the null or the $k-1$ model. All VIFs were below 1.6, indicating low multicollinearity. It is worth noting that neither Ara $\mathrm{h}$ 2-sIgE nor ps-IgE improved the model significantly. The performances of this composite marker were computed by ROC curve analysis and reached 0.84 (0.74-0.94) AUC. Best accuracy provided $97 \%$ Se (89-99) and 61\% Sp (49-71) (Figure 2).

The 3-variate composite marker predicting allergic reactions to peanut at cumulative dose $<100 \mathrm{mg}$ was the following formula: LCTG index $=1.60+0.18 \times$ age $-0.85 \times \log _{10}($ normalized basophil $\left.\mathrm{EC}_{50}\right)-0.052 \times \sqrt{ }(\mathrm{fMLP} \times \mathrm{FceRI})$-positive control values. An index score $>-0.69$ predicted a low-dose allergic reaction to peanut.

\section{DISCUSSION}

This study reports the relevance of a model of different composite markers in predicting both severity and cumulative threshold dose of an allergic reaction in children with PA and, for the first time to our knowledge, the relevance of an FceRI- and fMLP-positive control value alone.

\section{Demographic markers related to the severity and cumulative threshold dose of an allergic reaction during an OFC}

In our study, the children were older in the LCTG. These results corroborate those of the MIRABEL cohort in which an older age was identified as a predictor of low threshold reactivity. ${ }^{23}$

Similarly, in a double-blind, placebo-controlled study, Van der Zee et $\mathrm{al}^{19}$ showed that the eliciting dose of a peanut OFC was associated with a higher age. These results are similar to previous studies that showed that adolescents experience more severe allergic reactions to peanuts than younger children in real life. ${ }^{19}$

\section{Biological parameters related to the severity and cumulative threshold dose of an allergic reaction during an OFC \\ We found that Ara h 2-sIgE was related to the severity of an} allergic reaction during an OFC and to a lower cumulative threshold dose. These results corroborate those of Santos et $\mathrm{al}^{22}$ where patients with severe allergic reactions were shown to have higher Ara h 2-sIgE levels. A previous study found contradictory results about the relationship between Ara h 2 -sIgE and the risk of anaphylaxis, ${ }^{33}$ whereas others found no association between this biomarker and the severity of an allergic reaction to peanut. $^{34}$

Furthermore, some studies found that Ara h 2-sIgE levels determined the cumulative threshold dose during an OFC, with contradictory results observed in others. ${ }^{16,33,34}$

In our study, the relationship between Ara h 2-sIgE levels and lower reaction doses observed in univariate analysis disappeared in multivariable models once controlled for basophil reactivity.

Various BAT parameters were associated with severity (non-allergen-specific FceRI-positive control value) or cumulative threshold doses of an allergic reaction during an OFC 
TABLE III. Descriptive analysis of parameters associated with the cumulative threshold dose of an allergic reaction during a peanut oral food challenge

\begin{tabular}{|c|c|c|c|}
\hline & \multicolumn{3}{|c|}{ Cumulative threshold dose groups } \\
\hline & LGCT $^{*}(n=26)$ & HCTG $(n=30)$ & $P$ value \\
\hline \multicolumn{4}{|l|}{ Demographic characteristics } \\
\hline Age (y) & $8.2(56-11.0)$ & $12.4(7.7-14.1)$ & .02 \\
\hline Male/female (n) & $15 / 11$ & $21 / 9$ & \\
\hline Astier score (I/II/III/IV) & $7 / 11 / 6 / 2$ & $10 / 15 / 5 / 0$ & .24 \\
\hline Cumulative threshold dose (mg of pp) & $317(200-332)$ & $27.5(17-40)$ & - \\
\hline \multicolumn{4}{|l|}{ Biological parameters } \\
\hline Eosinophilia $\left(10^{6}\right.$ cells $\left./ \mathrm{mm}^{3}\right)$ & $0.47(0.31-0.62)$ & $0.40(0.31-0.56)$ & .58 \\
\hline Total IgE (kUI/L) & $662.5(242.5-1128.5)$ & $618(331-1123)$ & .61 \\
\hline Peanut-specific $\operatorname{IgE}\left(\mathrm{kU}_{\mathrm{A}} / \mathrm{L}\right)$ & $30.5(5.8-253.7)$ & $131(78.7-219)$ & .004 \\
\hline Ara h 2-specific $\operatorname{IgE}\left(\mathrm{kU}_{\mathrm{A}} / \mathrm{L}\right)$ & $11.8(3.6-115.5)$ & $62.4(37.7-98.9)$ & .001 \\
\hline Peanut-specific IgG4 (mg/L) & $0.37(0.1-1.6)$ & $0.56(0.28-1.18)$ & .25 \\
\hline Ara h 2-specific IgG4 (mg/L) & $0.09(0.05-0.36)$ & $0.18(0.077-0.51)$ & .30 \\
\hline \multicolumn{4}{|l|}{ Absolute peanut BAT parameters } \\
\hline Negative control & $0.3(0.01-1)$ & $0.4(0.01-0.975)$ & .69 \\
\hline FceRI-positive control & $86.4(76.3-92.3)$ & $83.2(76.9-89.8)$ & .73 \\
\hline fMLP-positive control & $35.4(23.1-46.5)$ & $32.1(20.8-43.9)$ & .33 \\
\hline Absolute percentage of basophil activation at $100 \mathrm{ng} / \mathrm{mL}$ of peanut extract & $56.3(36.7-85.4)$ & $75.1(60.6-87.0)$ & .06 \\
\hline Absolute percentage of basophil activation at $10 \mathrm{ng} / \mathrm{mL}$ of peanut extract & $29.6(2.7-62.5)$ & $75.8(48.5-88.3)$ & .002 \\
\hline Absolute percentage of basophil activation at $1 \mathrm{ng} / \mathrm{mL}$ of peanut extract & $0.8(0.2-6.9)$ & $15(4.3-51.3)$ & .02 \\
\hline Absolute basophil $\mathrm{EC}_{50}{ }^{\ddagger}(\mathrm{ng} / \mathrm{mL})$ & $68.3(23.2-109.1)$ & $121.7(64.5-153.3)$ & .004 \\
\hline Absolute basophil activation AUC & $83.7(8.4-1000)$ & $5.4(0.1-47.5)$ & .02 \\
\hline \multicolumn{4}{|l|}{ Normalized peanut BAT parameters } \\
\hline Normalized percentage of basophil activation at $100 \mathrm{ng} / \mathrm{mL}$ of peanut extract & $81.1(62.6-93.8)$ & $97.0(86.0-100.9)$ & .01 \\
\hline Normalized percentage of basophil activation at $10 \mathrm{ng} / \mathrm{mL}$ of peanut extract & $31.5(3.9-87.0)$ & $98.4(71.6-106.0)$ & .0003 \\
\hline Normalized percentage of basophil activation at $1 \mathrm{ng} / \mathrm{mL}$ of peanut extract & $1.1(0.3-8.6)$ & $24.7(5.4-61.2)$ & .01 \\
\hline Normalized basophil $\mathrm{EC}_{50}^{\ddagger}(\mathrm{ng} / \mathrm{mL})$ & $74.4(38.8-149.4)$ & $169.0(121.8-188.1)$ & .001 \\
\hline Normalized basophil activation AUC & $43.3(5.3-79.1)$ & $2.8(0.1-7.0)$ & .001 \\
\hline
\end{tabular}

Values are expressed as numbers or medians (interquartile ranges). $P$ values $<.05$ are boldface for 2 group comparisons of qualitative variables by using Fisher's exact test and for 2 group comparisons of quantitative variables by using permutation 1-way analysis tests.

$A U C$, Area under the curve; $B A T$, basophil activation test; $p p$, peanut protein.

*LGCT $=$ low cumulative threshold dose group $\leq 100 \mathrm{mg}$ of peanut ( $28 \mathrm{mg}$ of peanut protein).

$\dagger$ HCTG = high cumulative threshold dose group $>100 \mathrm{mg}$ of peanut ( $28 \mathrm{mg}$ of peanut protein).

$\ddagger \mathrm{EC}_{50}=$ allergen concentration able to activate $50 \%$ of basophils.

(normalized basophil Se to peanut $\left[\mathrm{EC}_{50}\right]$ and non-allergenspecific FceRI- and fMLP-positive control value).

Contrary to our results, Song et $\mathrm{al}^{20}$ showed a correlation between the severity of an allergic reaction during an OFC and the percentage of basophil activation at a specific concentration of peanut $(200 \mathrm{ng} / \mathrm{mL}$ of allergen $r=0.50, P<.0001)$. This study focused on BAT parameters of basophil activation at a given concentration of peanut extract or component without taking into account the nonspecific basophil activation to an FceRI-positive control value.

However, Santos et $\mathrm{al}^{22}$ found that the association between severity and allergen-specific BAT parameters was improved when the value of the FceRI-positive control was taken into account. Chinthrajah et $\mathrm{al}^{35}$ demonstrated that the $\mathrm{CD}^{+} 3^{+}$ peanut/anti-IgE ratio was the best predictor of a severe allergic reaction with a regression model. Finally, in a study on cow's milk allergy, this ratio was strongly correlated with the severity but also, as in our study, with the threshold dose of the allergic reaction. ${ }^{36}$ However, in our study, we found that Ara h 2-sIgE levels appear more relevant than allergen-specific BAT parameters to predict severity, but that, similar to Santos et al's study, ${ }^{22}$ the FceRI-positive control value added information to this allergen-specific parameter, indicating the activation potential of the patient's basophils.

Several studies have demonstrated the usefulness of the BAT to predict the cumulative threshold dose during an OFC. ${ }^{22,37,38}$ In our study, lower normalized basophil $\mathrm{EC}_{50}$ levels were associated with the LCTG, even after controlling for age and an FceRI-positive control value. Previous studies have already demonstrated the value of $\mathrm{CD}$-sens $\left(1 / \mathrm{EC}_{50}\right)$ for predicting the threshold dose. ${ }^{22,38}$ Santos et al ${ }^{22}$ also showed that CD-sens was more discriminative in predicting the threshold dose. ReierNilsen et $\mathrm{al}^{37}$ found that basophil activation was the best predictor of a very low reactivity threshold in children presenting anaphylaxis to peanut. Chapuis et $\mathrm{al}^{38}$ confirmed the close link between the percentage of $\mathrm{CD}^{+} 3^{+}$basophils or CD203c and threshold dose.

Our study suggests for the first time that the allergenindependent basophil parameters such as FceRI- and fMLPpositive control values are associated with the severity of 


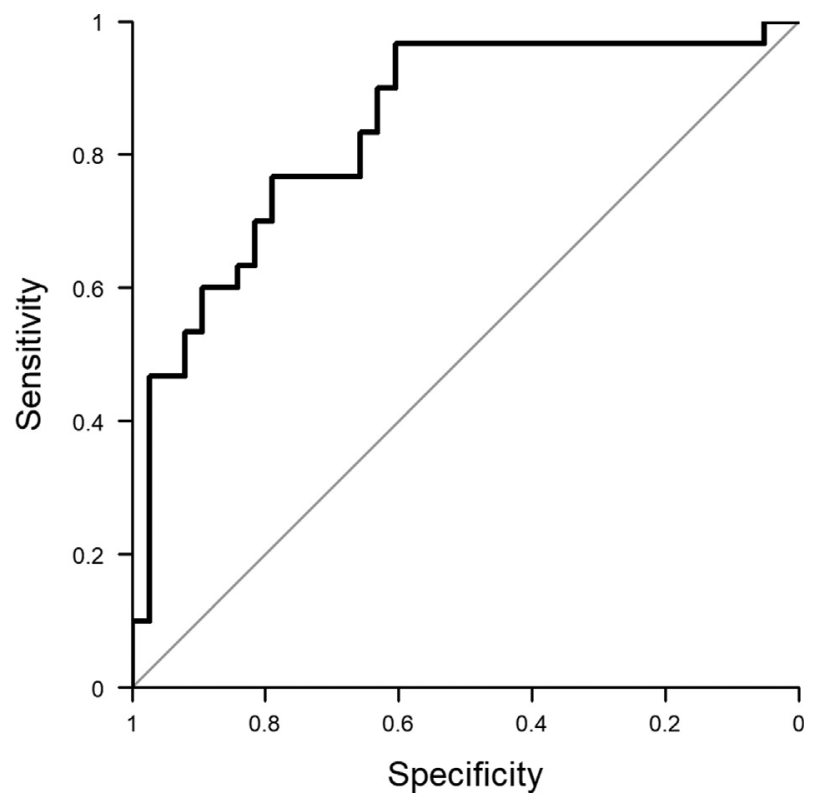

FIGURE 2. Receiver operating characteristic curve of the multivariable logistic regression model presented in Table II (lower part) comparing the performances of this model in discriminating peanut-allergic children reacting to low or high dose of peanut proteins.

peanut-allergic reactions, independently of Ara h 2-sIgE levels. This result is concordant with a decrease in BAT FceRI-positive control during peanut oral immunotherapy. ${ }^{39,40}$ The value of the FceRI-positive control probably reflects the potential of maximum percentage of nonspecific basophil activation, similar to serum tryptase levels in severe hymenoptera venom allergy in patients with mastocytosis. ${ }^{41}$

On the other hand, allergen-specific basophil reactivity is an independent factor and is related to the threshold dose of an allergic reaction, as can be observed during oral immunotherapy.

\section{Composite markers most accurately predict the severity and cumulative threshold dose of an allergic reaction during an OFC}

In our 2 models, different composite markers predicted severity and the cumulative threshold dose. This difference is probably because severity and cumulative threshold dose are not related either in our study or in the literature.

However, only 1 parameter-a higher FceRI-positive control value-was common to both composite markers linked to severity and cumulative threshold. This factor (FceRI-positive control value) probably reflects an "intrinsic severity" linked to the fact that oral immunotherapy is more easily performed in young children perhaps in relationship to immune plasticity. ${ }^{42}$

In our study, composite markers including age and FceRIpositive control value were the best predictor of the severity of an allergic reaction during an OFC. Similarly, Chinthrajah et $\mathrm{al}^{35}$ showed that a history of exercise-induced asthma and CD63 ratio were statistically significant predictors of challenge severity score using a LASSO (least absolute shrinkage and selection operator) regression model.
Furthermore, the best model to predict cumulative threshold included both demographic (age) and biological parameters (normalized basophil activation at $1 \mathrm{ng} / \mathrm{mL}$ of peanut extract, FceRI-positive control value, and Ara h 2-sIgG4). In the same manner, in the MIRABEL cohort, composite parameters including gender, prick test size, and Ara h 2-sIgE were found to predict the threshold dose. ${ }^{23}$

\section{Strengths and limits}

The strength of our study lies in the nature of our wellcharacterized sample. Furthermore, the OFCs were performed during 1 day and with similar doses to other studies. ${ }^{22,23,37,38}$ However, the study was retrospective and the OFCs (as used in clinical practice) were not performed in a double-blind placebocontrolled manner. ${ }^{43}$ Another limit is that allergic comorbidities, such as asthma or atopic dermatitis, were not included in the model as in other studies. However, we did not see any relationship between levels of total IgE and the FceRI-positive control value (data not shown). Finally, the sample size and the absence of an independent validation cohort are also limitations.

\section{Perspective}

Multivariable BAT is increasingly recognized as a surrogate marker for an OFC. Kits for performing the BAT are now readily available making this analysis feasible for any medical laboratory with a flow cytometer. Thus, the BAT can now be routinely performed in any allergy clinic with access to a laboratory service, and we suggest that the BAT is offered to all children with ps-IgE sensitization and suspected PA. The multivariable biomarkers we present here could therefore be used in clinical practice to determine the severity and threshold dose of an allergic reaction, without the need of an OFC. These results must now be validated with other food allergens in larger prospective cohorts.

\section{Acknowledgments}

We thank Marie-Ange Selva, ME, for technical assistance, and Paluel-Marmont Colombe, MD, and Dr Tallon Pauline, MD, for their cooperation.

\section{REFERENCES}

1. Sicherer SH, Sampson HA. Food allergy. J Allergy Clin Immunol 2010;125: S116-25.

2. Dyer AA, Rivkina V, Perumal D, Smeltzer BM, Smith BM, Gupta RS. Epidemiology of childhood peanut allergy. Allergy Asthma Proc 2015;36: 58-64.

3. Deschildre A, Elegbédé CF, Just J, Bruyère O, Van der Brempt X, Papadopoulos A, et al. Peanut-allergic patients in the MIRABEL survey: characteristics, allergists' dietary advice and lessons from real life. Clin Exp Allergy 2016;46:610-20.

4. Sicherer SH, Muñoz-Furlong A, Godbold JH, Sampson HA. US prevalence of self-reported peanut, tree nut, and sesame allergy: 11-year follow-up. J Allergy Clin Immunol 2010;125:1322-6.

5. Nwaru BI, Hickstein L, Panesar SS, Roberts G, Muraro A, Sheikh A, et al. Prevalence of common food allergies in Europe: a systematic review and metaanalysis. Allergy 2014;69:992-1007.

6. Wang Y, Allen KJ, Suaini NHA, McWilliam V, Peters RL, Koplin JJ. The global incidence and prevalence of anaphylaxis in children in the general population: a systematic review. Allergy 2019;74:1063-80.

7. Turner PJ, Gowland MH, Sharma V, Ierodiakonou D, Harper N, Garcez T, et al. Increase in anaphylaxis-related hospitalizations but no increase in fatalities: an analysis of United Kingdom national anaphylaxis data, 1992-2012. J Allergy Clin Immunol 2015;135:956-963.e1.

8. Grabenhenrich LB, Dölle S, Moneret-Vautrin A, Köhli A, Lange L, Spindler T, et al. Anaphylaxis in children and adolescents: The European Anaphylaxis Registry. J Allergy Clin Immunol 2016;137:1128-11237.e1. 
9. Skolnick HS, Conover-Walker MK, Koerner CB, Sampson HA, Burks W, Wood RA. The natural history of peanut allergy. J Allergy Clin Immunol 2001; 107:367-74.

10. Neuman-Sunshine DL, Eckman JA, Keet CA, Matsui EC, Peng RD, Lenehan PJ, et al. The natural history of persistent peanut allergy. Ann Allergy Asthma Immunol 2012;108:326-331.e3.

11. Stensgaard A, Bindslev-Jensen C, Nielsen D, Munch M, DunnGalvin A. Quality of life in childhood, adolescence and adult food allergy: patient and parent perspectives. Clin Exp Allergy 2017;47:530-9.

12. NIAID-Sponsored Expert PanelBoyce JA, Assa'ad A, Burks AW, Jones SM Sampson HA, et al. Guidelines for the diagnosis and management of food allergy in the United States: report of the NIAID-sponsored expert panel J Allergy Clin Immunol 2010;126:S1-58.

13. Perry TT, Matsui EC, Conover-Walker MK, Wood RA. Risk of oral food challenges. J Allergy Clin Immunol 2004;114:1164-8.

14. Sampson HA, Ho DG. Relationship between food-specific IgE concentrations and the risk of positive food challenges in children and adolescents. J Allergy Clin Immunol 1997;100:444-51.

15. Dang TD, Tang M, Choo S, Licciardi PV, Koplin JJ, Martin PE, et al. Increasing the accuracy of peanut allergy diagnosis by using Ara h 2. J Allergy Clin Immunol 2012;129:1056-63.

16. Lieberman JA, Glaumann S, Batelson S, Borres MP, Sampson HA Nilsson C. The utility of peanut components in the diagnosis of IgEmediated peanut allergy among distinct populations. J Allergy Clin Immunol Pract 2013;1:75-82.

17. Santos AF, Douiri A, Bécares N, Wu S-Y, Stephens A, Radulovic S, et al Basophil activation test discriminates between allergy and tolerance in peanutsensitized children. J Allergy Clin Immunol 2014;134:645-52.

18. Ebo DG, Bridts CH, Hagendorens MM, Aerts NE, De Clerck LS, Stevens WJ Basophil activation test by flow cytometry: present and future applications in allergology. Cytometry B Clin Cytom 2008;74:201-10.

19. Van der Zee T, Dubois A, Kerkhof M, van der Heide S, Vlieg-Boerstra B. The eliciting dose of peanut in double-blind, placebo-controlled food challenges decreases with increasing age and specific $\operatorname{IgE}$ level in children and young adults. J Allergy Clin Immunol 2011;128:1031-6.

20. Song Y, Wang J, Leung N, Wang LX, Lisann L, Sicherer SH, et al. Correlations between basophil activation, allergen-specific $\operatorname{IgE}$ with outcome and severity of oral food challenges. Ann Allergy Asthma Immunol 2015 114:319-26.

21. Blumchen K, Beder A, Beschorner J, Ahrens F, Gruebl A, Hamelmann E, et al. Modified oral food challenge used with sensitization biomarkers provides more real-life clinical thresholds for peanut allergy. J Allergy Clin Immunol 2014 134:390-8.

22. Santos AF, Du Toit G, Douiri A, Radulovic S, Stephens A, Turcanu V, et al Distinct parameters of the basophil activation test reflect the severity and threshold of allergic reactions to peanut. J Allergy Clin Immunol 2015;135: 179-86.

23. Elegbede CF, Papadopoulos A, Just J, Moneret-Vautrin DA, Deschildre A, Crépet A. Gender, prick test size and rAra h 2 sIgE level may predict the eliciting dose in patients with peanut allergy: evidence from the Mirabel survey. Clin Exp Allergy 2019:49:677-89.

24. Sugiura S, Sasaki K, Matsui T, Nakagawa T, Kando N, Ito K. Development of a prediction model for a severe reaction in cow's milk challenges. Allergol Int 2017;66:493-4

25. Sugiura S, Matsui T, Nakagawa T, Sasaki K, Nakata J, Kando N, et al. Development of a prediction model of severe reaction in boiled egg challenges. Allergol Int 2016;65:293-9.
26. Sugiura S, Matsui T, Furuta T, Sasaki K, Kando N, Ito K. Development of a prediction model for severe wheat allergy. Pediatr Allergy Immunol 2018;29: 93-6.

27. Cox LS, Sanchez-Borges M, Lockey RF. World Allergy Organization Systemic Allergic Reaction Grading System: is a modification needed? J Allergy Clin Immunol Pract 2017;5:58-62.e5.

28. Ewan PW, Clark AT. Long-term prospective observational study of patients with peanut and nut allergy after participation in a management plan. Lancet 2001;357:111-5.

29. Astier C, Morisset M, Roitel O, Codreanu F, Jacquenet S, Franck P, et al. Predictive value of skin prick tests using recombinant allergens for diagnosis of peanut allergy. J Allergy Clin Immunol 2006;118:250-6.

30. Hourihane JO, Allen KJ, Shreffler WG, Dunngalvin G, Nordlee JA, Zurzolo GA, et al. Peanut Allergen Threshold Study (PATS): novel single-dose oral food challenge study to validate eliciting doses in children with peanut allergy. J Allergy Clin Immunol 2017;139:1583-90.

31. Blom WM, Vlieg-Boerstra BJ, Kruizinga AG, van der Heide S, Houben GF, Dubois AEJ. Threshold dose distributions for 5 major allergenic foods in children. J Allergy Clin Immunol 2013;131:172-9.

32. L'Entrepôt de Données de Santé | Délégation à la Recherche Clinique et à l'Innovation de l'AP-HP. Available from: https://recherche.aphp.fr/eds/. Accessed September 10, 2019.

33. Wainstein BK, Studdert J, Ziegler M, Ziegler JB. Prediction of anaphylaxis during peanut food challenge: usefulness of the peanut skin prick test (SPT) and specific IgE level. Pediatr Allergy Immunol 2010;21:603-11.

34. Summers CW, Pumphrey RS, Woods CN, McDowell G, Pemberton PW, Arkwright PD. Factors predicting anaphylaxis to peanuts and tree nuts in patients referred to a specialist center. J Allergy Clin Immunol 2008;121: 632-638.e2.

35. Chinthrajah RS, Purington N, Andorf S, Rosa JS, Mukai K, Hamilton R, et al. Development of a tool predicting severity of allergic reaction during peanut challenge. Ann Allergy Asthma Immunol 2018;121:69-76.e2.

36. Rubio A, Vivinus-Nébot M, Bourrier T, Saggio B, Albertini M, Bernard A. Benefit of the basophil activation test in deciding when to reintroduce cow's milk in allergic children. Allergy 2011;66:92-100.

37. Reier-Nilsen T, Michelsen MM, Lødrup Carlsen KC, Carlsen K-H, Mowinckel P, Nygaard UC, et al. Predicting reactivity threshold in children with anaphylaxis to peanut. Clin Exp Allergy 2018;48:415-23.

38. Chapuis A, Thevenot J, Coutant F, Messaoudi K, Michaud E, Pereira B, et al. Ara $\mathrm{h} 2$ basophil activation test does not predict clinical reactivity to peanut. J Allergy Clin Immunol Pract 2018;6:1772-1774.e1.

39. Chinthrajah RS, Purington N, Andorf S, Long A, O'Laughlin KL, Lyu SC, et al. Sustained outcomes in oral immunotherapy for peanut allergy (POISED study): a large, randomised, double-blind, placebo-controlled, phase 2 study. Lancet 2019;394:1437-49.

40. Tsai M, Mukai K, Chinthrajah RS, Nadeau KC, Galli SJ. Sustained successful peanut oral immunotherapy associated with low basophil activation and peanutspecific IgE. J Allergy Clin Immunol 2020;145:885-896.e6.

41. Stoevesandt J, Sturm GJ, Bonadonna P, Oude Elberink JNG, Trautmann A. Risk factors and indicators of severe systemic insect sting reactions. Allergy 2020;75: $535-45$.

42. Soller L, Abrams EM, Carr S, Kapur S, Rex GA, Leo S, et al. First real-world safety analysis of preschool peanut oral immunotherapy. J Allergy Clin Immunol Pract 2019;7:2759-2767.e5.

43. Venter C, Pereira B, Voigt K, Grundy J, Clayton CB, Gant C, et al. Comparison of open and double-blind placebo-controlled food challenges in diagnosis of food hypersensitivity amongst children. J Hum Nutr Diet 2007;20:565-79. 
TABLE E1. Astier score: systemic allergic reaction grading system

Grade

Symptoms

No symptoms

$1 \quad$ Abdominal pain that resolved without requiring medical treatment, rhinoconjunctivitis, urticaria fewer than 10 papulas, rash (eczema onset)

2

One organ involved, abdominal pain requiring treatment, generalized urticaria, nonlaryngeal angioedema, mild asthma (cough or fall of peak expiratory flow $<20 \%$ )

3 Two organs involved

4 Three organs involved or asthma requiring treatment or laryngeal edema or hypotension

5 Cardiac and respiratory symptoms requiring hospitalization in intensive care 